\title{
Reducing Personal Emissions in Response to Collective Harm
}

\section{Cassidy Robertson ${ }^{1}$ (D)}

Accepted: 8 February 2021 / Published online: 1 April 2021

(C) The Author(s) 2021

\begin{abstract}
Anthropogenic climate change threatens humanity as a whole, making its mitigation a matter of pressing concern. Mitigation efforts at the institutional level are necessary to successfully change the course of climate change, but thus far governments and industries have been ineffective at reducing greenhouse gas emissions. A point of philosophical contention is whether individuals have a moral responsibility to reduce their own emissions given the lack of institutional action. I argue that they do by redefining climate change as a collective impact. Individual emitters share collective responsibility for that impact, which translates to an individual duty to reduce their contribution.
\end{abstract}

Keywords Collective harm · Collective impact $\cdot$ Personal responsibility $\cdot$ Individual responsibility $\cdot$ Climate change $\cdot$ Greenhouse gas emissions $\cdot$ Personal emissions

The fact of climate change is incontrovertible, as is the fact that anthropogenic greenhouse gas (GHG) emissions are a significant driver thereof: the IPCC estimates that greenhouse gases emitted by human activities up to now are responsible for $1{ }^{\circ} \mathrm{C}$ of warming over preindustrial levels, and will result in a net increase of $1.5^{\circ} \mathrm{C}$ between 2030 and 2052 at current emission rates $(2018$, p. 4). A temperature increase of between 1.5 and $2{ }^{\circ} \mathrm{C}$ is projected to cause widespread damage to (and sometimes permanent loss of) marine and terrestrial ecosystems, an increase in extreme weather events such as droughts, high temperatures, heavy rainfall, and a rise in sea levels. These changes will have a variety of negative effects on human health, food and water security, and will dampen economic growth (IPCC, 2018, pp. 7-10).

These risks are not merely hypothetical or projected. A decrease in cold days, an increase in heatwaves, and extreme sea levels have all been observed and can be confidently attributed, at least in part, to human influence. Additionally, losses

Cassidy Robertson

cassidy.m.robertson@gmail.com

1 Karl-Franzens-Universität Graz, Graz, Austria 
associated with extreme weather events have also trended upwards. As human populations continue to grow, exposure of human populations to extreme weather events increases; this is projected to further increase damages (Mechler et al., 2019, pp. 63-78). Climate change has already led to the destruction of homes and crops on the island of Mousuni, and the nation of the Maldives is constantly losing ground to sealevel rise (Banks, 2013, p. 43). In order to avoid the most catastrophic consequences of climate change, the IPCC recommends targeting a net temperature increase of no more than $2{ }^{\circ} \mathrm{C}$. This goal requires immediate and comprehensive action: $\mathrm{CO}_{2}$ emissions must be reduced by around $25 \%$ by 2030 , eventually reaching net zero around 2070 (2018, pp. 10, 12).

The urgency and significance of climate change is not lost on philosophers. There is widespread agreement that we-specifically our institutions and governing bodies-ought to take action to mitigate its impacts, and in fact are morally obligated to do so (Fahlquist, 2009; Maltais, 2013; Sinnott-Armstrong, 2005, among others). The question of whether individuals also bear a moral responsibility to unilaterally reduce their GHG emissions (that is, absent any collective agreements or legal restrictions compelling them to do so) has proven more divisive.

Walter Sinnott-Armstrong's (2005) paper 'It's not my fault: global warming and individual moral obligations,' in which he argues that there is no such individual obligation, has been paradigmatic to the entire debate, with a discourse growing around defenses of and rebuttals to it. I will use it as a template for arguments against individual moral responsibility and in responding to it, I will develop my thesis that we do have an individual moral obligation to reduce our GHG emissions. I begin by summarizing the inefficacy problem, the central pillar of Sinnott-Armstrong's and similar arguments, and refute it by recharacterizing climate change as a collective impact. Individual responsibility for climate change arises directly from its collective nature, and from this responsibility I derive a duty for individuals to develop emissions-reducing, green habits.

\section{The Argument Against an Individual Moral Obligation}

In his paper, Sinnott-Armstrong asks whether, in the absence of government action, the facts of global warming provide him a moral obligation to refrain from a Sunday afternoon joyride in a gas-guzzling SUV (2005, p. 296). His arguments apply broadly to the emission of GHGs; his purpose in choosing this specific example is to distinguish reducing personal emissions from other individual actions which could potentially work to mitigate climate change, such as lobbying politicians or working to educate his community about global warming. For the purposes of this paper, I will expand the scope of the actions in question slightly further to include, for example, buying regional produce or separating garbage-actions which only indirectly emit or refrain from emitting GHGs - to address the complete cross-section of personal-emissions-reducing actions, and use the joyriding example for illustrative purposes.

Sinnott-Armstrong states openly that it may be morally better not to gas-guzzle for the sake of fun, and even admits that "global warming does 'seem' to make such 
wasteful driving morally wrong" (2005, p. 296). Nevertheless, in the end he concludes that there is no moral reason to refrain from joyriding. Two premises lead him to this conclusion: firstly, that individual GHG emissions are too minor to make any difference to how much climate change happens; and secondly, that there can be no moral obligation to act or not act when doing so does not make a difference. In this paper I focus on his first premise. The question is, essentially, what impact can an individual's actions have on climate change?

GHGs are naturally present in the atmosphere, where they have drifted harmlessly for millennia. They serve an important function in keeping our planet a livable temperature. Water vapor builds clouds and brings rain, and $\mathrm{CO}_{2}$ is vital for plant growth. They only become harmful at unnaturally high concentrations like we see now. These emissions entered the atmosphere at the hands of countless factory workers, campfire builders, beef farmers, and Sunday joyriders over the course of the past century and a half. There are over seven billion people on the earth, almost all of whom benefit in some way from current and past emissions and who continue to emit today.

In the face of these incomprehensibly large numbers, the amount of GHGs emitted by one person over the course of their life is miniscule, too negligible to make any directly measurable difference to the current atmospheric stock. The impact from a single Sunday joyride is even smaller. The GHGs I would not emit by refraining from a Sunday joyride would be equally negligible. Moreover, an equivalent amount would be almost immediately emitted from another source; assuming that my not emitting had any effect whatsoever, the net result would only have been to postpone the emissions by a fraction of a second. Extrapolating from this, it can be difficult to see how my individual emissions are even relevant-as Sinnott-Armstrong says, emptying a jug of water into a river swollen by torrential rains, "my act of pouring the quart into the river is not the cause of the flood" (2005, p. 298). If my action makes no difference either way, why should I bother?

\section{Difference-Making and Collective Impact}

Before proceeding further, it's important to discuss what climate change is a bit more closely. In a purely scientific sense, I am referring to changes in global climate patterns resulting from anthropogenic GHG emissions. The high GHG levels responsible for our impending climate crisis are the cumulative result of a century and a half of human activity and, as I alluded to above, one person's emissions are proportionally insignificant. This makes climate change a prime example of what Julia Nefsky calls a 'collective impact case,' in which "people can collectively cause some morally significant outcome ... but no individual act seems to make a difference" (2017, p. 2744). She lists a number of collective impact cases, from voting to donations to OXFAM, which all can fall victim to the same "why should I bother?" attitude.

But if individual actions in such cases don't make a difference, how does the morally significant outcome arise? If we disregard individual acts, we're left with the preposterous explanation that it is somehow self-generating-that OXFAM's 
operating budget spontaneously appears in their bank account and that a winner emerges from the ballot box as if by immaculate conception. Saying that my individual actions play no role in causing climate change is the same as saying that my actions are insufficient to cause climate change or, more quotably, "if I joy-ride in my " 57 Chevy, but no one else ever emits any GHGs, then there would be no [anthropogenic global climate change]," which Avram Hiller dismisses out of hand:

...causal claims about the effects of actions that are conditional on the world being very different from the way it actually is (and is known to be) are normally irrelevant in assessing the morality of the action. Furthermore, one would not be able to go for a joy-ride in a '57 Chevy unless there were an entrenched system of cars, roads, oil-drilling, gas stations, etc. Thus the idea of a single joyride in isolation of other GHG-emitting activities is hardly intelligible. (2011, p. 351)

Clearly we must account for individual actions in assessing collective impact cases, but how can we square that with the equally self-evident fact that the actions of one person will not produce a different outcome? By simply dropping the assumption that "if an act will not make a difference with respect to an outcome, then it cannot do anything non-superfluous toward bringing that outcome about" (Nefsky, 2017, p. 2746). In other words, the fact that an act doesn't make a difference to the outcome does not mean that it doesn't contribute to the outcome.

Imagine a city council election in a small town with 101 voters. Two candidates, Norma and Ed, are running, and whoever gets the majority of votes will be declared winner. Polls close, votes are tallied, and Norma wins with 51 votes. At Norma's victory celebration some of her supporters get to talking and one, already a few drinks in, loudly complains that only one voter's action actually made a difference: the 51st person to vote for Norma. The rest of Norma's voters are now disappointed; they all wanted to make an important difference too! In the next election, they all privately decide not to cast their votes until 50 other people have already voted for Norma-after all, why waste their votes by voting earlier, if they wouldn't have a chance to make a difference? The results are unprecedented! Norma has no votes, while Ed wins with 50. Aghast, the voters realize their mistake: every vote leading up to vote 51 was equally necessary to get Norma elected, even if they didn't individually determine the result.

Nefsky refers to such actions, which contribute to an outcome without actually determining it, as helping to bring that outcome about, where helping means "playing a non-superfluous causal role in the occurrence of an outcome" (Nefsky, 2017, p. 2746). All of Norma's votes did help in the example above, but this needn't always be the case. Suppose that a few years later Norma retires and Hank, a less popular candidate, takes her place. Hank only gets 40 votes while Ed wins with 61 . In this case votes 1-40 helped get Ed elected, vote 41 made the difference, and votes 42-61 were superfluous because the outcome had already been decided when they were cast. Of course, it could be argued that vote 51 still made the difference because it was the first vote that guaranteed Ed's win, or, since the decisive number of votes can only be determined retrospectively once the votes are counted, that every vote 
made without that knowledge still helped; Nefsky examines these distinctions more closely, but they are irrelevant for discussing climate change.

Election results hinge on a clear threshold: fewer than $\mathrm{X}$ votes and one loses, $\mathrm{X}$ or above and one wins. In this sense they are disanalogous to climate change, which does not exhibit a stepwise pattern of thresholds - the global thermometer does not tick higher with every 500th act of GHG emission or every 500th ton of $\mathrm{CO}_{2}$. (Except, perhaps, in certain games of moral mathematics which Nefsky dismisses as often leading to problematic moral verdicts $(2019$, p. 8).) The relationship between emissions and climate change is a continuous one, so every act of emission will have an effect on climate change. Indeed, a number of climatic feedback loops (such as melting pack ice decreasing the Earth's albedo, which accelerates the loss of pack ice, and so on) mean that the proportional impact of continuing emissions will actually increase over time. There is no ceiling to climate change, either: we will continue to have an effect on the climate as long as we continue to emit GHGs even as we pass important climatic tipping points, such as the IPCC's less-than-twodegree target. In short, every act that emits GHGs helps to sharpen the collective impact of climate change.

\section{Responsibility for Collective Harm}

Even accepting that all emissions help to worsen climate change, it can be difficult to derive any individual moral obligations from that fact. The mere ability to contribute to an outcome does not inherently oblige one to do so. What's more, the problem of inefficacy is still looming. After all, each of the billions of tons of cement produced annually corresponds to $900 \mathrm{~kg}$ of $\mathrm{CO}_{2}$ released into the atmosphere (Benhelal, 2013, p. 142) — the few grams produced by my Sunday joyride are, though non-zero, a pittance in comparison. Sinnott-Armstrong compares emitting GHGs to "poisoning someone who is already dying from poison," though he rejects this notion on the grounds that individual emissions are too insignificant to even qualify as poison (2005, p. 299). But even if my emissions aren't insignificant, the objection could be raised that they are irrelevant. There are already enough GHGs being emitted to guarantee the worst harms of climate change if they continue unabated, so mine merely help to increase the degree of overdetermination. Correspondingly, my individually refraining from emitting will not contribute to preventing any perceptible amount of harm-I would merely make that harm infinitesimally less overdetermined. In light of this Sinnott-Armstrong concludes that, rather than focusing one's effort on reducing their emissions, "it is better to enjoy your Sunday driving while working to change the law so as to make it illegal for you to enjoy your Sunday driving" (2005, p. 312).

Sinnott-Armstrong treats climate change like an ongoing process akin to the weathering of a bridge here, where the only choice an individual faces is whether or not to drive across it and perhaps imperceptibly accelerate its degradation. His conclusion is perfectly reasonable under this conception-if I see a worrisome frost crack in the concrete, the crack will continue to develop unhindered whether 
I drive or not, so I might as well keep my commute the same but write a letter to the mayor expressing my concern.

However, that conception of climate change ignores its collective nature. A more apt bridge-based analogy is that of the devotional padlock. Suppose that I and my sweetheart are strolling through the city one sunny afternoon. We are truly, deeply in love and want to commemorate that fact Pont-des-Arts-style, so we pop into a hardware store and select a sturdy padlock. We carve our initials, the date, and a plethora of hearts onto it as we make our way towards the river. But upon arriving at the bridge, we see that the safety railing is buckling under the weight of thousands of locks that it was never meant to support. To nevertheless clip my padlock on while resolving to start a petition banning the practice feels contradictory, if not downright hypocritical.

I don't bring up this example to examine the implications of such moral inconsistency_-Hourdequin addresses this topic at length (2010)—but rather to illustrate the strong moral intuition that can still arise in collective impact cases. The cause of bridge damage in this example is clear: too many padlocks. It is "not the result of some blameless, unpredictable, and/or natural cause, but, rather, ... caused by identifiable people who are acting in ways that are by choice, not by necessity" (Banks, 2013, p. 48). Clipping my padlock among the others is unlikely to cause the railing to collapse, but I'm still contributing to the problem in a very tangible way.

Yet even if the railing did collapse the instant I added my padlock, it doesn't seem reasonable to say that I alone bear the responsibility for the damage. So who does? The tourist who clipped 15 locks from all their friends and relatives back home? The person who added the heaviest one? The very first person to clip a lock to this bridge? Because they still ignore the collective nature of the damage, each of these solutions fails to adequately encompass its causality. Every person who added a lock helped to bring about its eventual collapse, so it follows that the responsibility falls on the entire collective. Such an assertion can be difficult to support under the framework of traditional ethics, however: most work examining collective responsibility evaluates it by the same standards as for individual responsibility, namely that "agents (or collective agents) need to have caused the act in question and must know that they have caused it" (Banks, 2013, p. 46). This approach makes it easy to assign collective responsibility to highly structured groups like the board of a company or the leaders of a nation, where they function as a single decision-making entity analogous to an individual. The group of all GHG emitters displays no such structure, making it impossible to ascribe any sort of coordinated action or decision to it.

Yet GHG emitters can be viewed as constituting a putative group which, despite being neither formalized nor acknowledged by its members, is responsible for collective harms resulting from the accumulation of individual acts (Cripps, 2011, p. 172). Accordingly, just as individuals causing harm have a duty to cease harm and make reparations, the putative group has a duty to "end the harm and/or to repair or compensate for the damage" (p. 178); because the collective harm arises from the accumulation of individual actions, fulfilling the duty to end the harm falls to the individuals performing them. Schwenkenbecher summarizes Cripps' argumentation as follows: 
The putative group which causes morally significant harm acquires (positive) duties to do something about that harm. Any individual who forms part of the group by performing individually those acts which in aggregation cause the harm acquires corresponding derivative moral duties. (2014, p. 174)

The upshot of defining putative groups as unacknowledged and unstructured is that they and the harms they cause, and thus the contributions of individual actions to these harms, can only be determined retroactively - the impact must be identified before the group responsible, so to speak. This limits the duties of putative groups to positive, corrective ones and means that this treatment of collective responsibility can only demand remedial action of individuals (Schwenkenbecher, 2014, p. 185); they do not have a negative duty to refrain from the actions that cause the harm in the first place, because to do so would require preemptively acknowledging membership in the putative group.

Melany Banks takes a similar tack in assessing responsibility for climate change, but one that does not preclude negative duties. Banks prefers the terms 'group causing harm' or 'collective,' but her concept shares the relevant traits of being unstructured, unacknowledged, and capable of collective harm, so I will continue to refer to it as a putative group to distinguish it from organized collectives. To get around the unstructured nature of GHG emitters, she conceptualizes the putative group not as an active agent, but rather as the context in which an individual acts. She suggests the following criteria to determine who, precisely, is eligible for membership in the responsible collective and thus eligible to bear personal responsibility:

An agent is a member of a group causing harm if and only if she participates in a collective action by:

1. reciprocally providing solidarity and receiving identification (including public membership); or

2. causally contributing to the collective outcome; and

3. she is not participating in a recognized activity by combining action and language to publicly distance herself from, and denounce, the actions of the collective. (Banks, 2013, pp. 50-51)

(2) is obviously salient in regards to climate change; I have already established that any act of GHG emission is causally contributing to it. (1) and (3) serve to address the societal aspect of collectives-our actions do not take place in a vacuum, but instead shape and are shaped by the people around us. (1) makes it possible to include people in the group who, while they may not be personally responsible for emissions, are participants in a culture dependent on emissions, as well as making Banks' framework more widely applicable to other collective harms. (3) exempts individuals who have taken pains to distance themselves from the putative group and made efforts to mitigate their contributions to the collective harm. While these individuals may still fulfill (2), Banks contends that (3) is necessary to "acknowledge the collective nature of climate change... and underline[] both the difficulty and efficacy of public acts in opposition to the collective action" (2013, p. 52). The 
"efficacy" to which she refers is the possibility to influence the behavior of others. While this efficacy is perhaps most obviously wielded by climate activists like Al Gore or Greta Thunberg, it is certainly not limited to such celebrity personalities. Rather, it encompasses anybody whose efforts influence others to make a contribution by providing a positive example and raising awareness- "individual choices do not go unnoticed by fellow citizens" (Schwenkenbecher, 2014, p. 179), so such efforts must be taken into account.

Mere membership in the putative group does not necessarily translate to individual moral responsibility for the harm. A newborn baby in the car with its parents, for instance, would qualify for membership in the collective under condition (1), but is not individually responsible for the emissions. Banks introduces two further clauses to determine which individuals in the group bear moral responsibility: a causal and an epistemic condition. The causal condition states simply that an agent must have contributed causally to the harm without coercion $(2013$, p. 52). The epistemic condition, which requires that agents "know the nature of their act" (p. 52), proves a bit more complicated. Traditional interpretations are concerned only with what the agent consciously knows at the time of their act which, due to the unclear causal links between GHG emissions and discrete instances of harm as well as the relatively recent development of climate science, means that this criteria may not be met by most members of the collective. Banks responds to this issue by extending the epistemic condition, building on George Sher's critiques of the traditional limited epistemic condition. By restricting responsibility to cases where the agent has conscious, extemporaneous knowledge that they are acting wrongly, it absolves people of responsibility for e.g. their own poor judgment or inattention. As such, she contends that mere ignorance does not preclude responsibility: if an agent has evidence for the wrongness of an action but, due to the "interaction of his constitutive attitudes, dispositions, and traits," remains ignorant of that wrongness, that ignorance is his responsibility and he is responsible for the consequences of his act (2013, p. 53). This assigns responsibility based on what an agent reasonably should have known at the time of their action. When President Gerald Ford greenlit the construction of the Alaska Pipeline from the oil fields of northern Alaska to Port Valdez in 1975, the relationship between fossil fuels and climate change was only beginning to be widely recognized; when President Donald Trump issued an executive order enabling oil drilling in national parks in 2017, he did so in the face of decades of scientific evidence. Even though the emissions resulting from the two decisions are equally harmful, his willful ignorance means that only Trump bears individual moral responsibility for them.

What an agent can be expected to know has a spatial component, in addition to the temporal component discussed above. Knowledge of climate change requires access to education, which varies wildly around the globe-some people in underdeveloped regions may simply lack the information to meet the epistemic condition. A study examining surveys from 119 countries found that about $40 \%$ of adults globally were not aware of human contributions to climate change, mostly concentrated in countries like Bangladesh, Egypt, and India. In contrast, over $90 \%$ of adults in highly developed countries were conscious of it (Lee et al., 2015, pp. 1014-1018). The survey did not distinguish between climate change deniers, who are choosing 
to disregard evidence available to them, and people genuinely unaware of climate change, so the proportion of people in the developed world who meet Banks' epistemic condition may be even higher. Either way, people living in the countries where the majority of GHGs are emitted are also the most aware of the impacts of those emissions, and thus eligible to bear responsibility for them.

\section{Duties Arising from Collective Harm}

I will now attempt to define the duties arising from the individual responsibility discussed above. These duties should principally serve to offset the impact of the putative group; in this case, to ameliorate climate change caused by GHG emissions. Focusing on specific acts is too constricting in this case - an edict like "thou shalt not joyride" leaves open the possibility of idling my SUV by the volleyball court to use its stereo during a game, which is just as egregiously wasteful. The phenomenon of climate change is a cumulative one arising from the aggregation of countless acts by billions of individuals. The harm of these acts is only realized in aggregate, so a response to that harm must focus on their aggregation.

We can examine individual responsibility through the lens of aggregated action as well. While every act of GHG emission contributes to climate change, one single act does not encompass an individual's contributions nor can it be treated as characteristic-suppose that November 28th is selected as the day by which we should each assess our emissions, and on that day I just so happen to be flying from Munich to Seattle. One long-distance flight emits significantly more carbon than a short drive, but if I only fly long-distance once per year, it would be a questionable extrapolation to say that my total impact on climate change is greater than that of a commuter who drives to work on that day and every other. Likewise the CEO seated next to me: this flight is an exception for me, whereas they fly international multiple times a week. It would be unreasonable to contend that our impact is identical because we happen to be on the same flight. My relationship with climate change does not hinge this one flight, nor from any other single act, but can only be established in light of them all. This concept is perhaps most familiar in the context of a carbon footprint, which estimates the amount of GHGs emitted, directly and indirectly, by an individual, expressed as carbon equivalents. I do not wish to tie individual duties to any specific metric because differing measurement standards and varying estimations could make it difficult to apply consistently. Nevertheless, the carbon footprint is a helpful way to conceptualize the aggregation of emitting acts: the more often I engage in emissions-producing activities the higher my carbon footprint, and the higher my carbon footprint the greater my cumulative contribution to climate change. Thus, as a member of the collective of GHG emitters, I bear the negative duty to refrain from emissions-producing activities.

This is an impossibly broad mandate. Emissions-producing activities are integrated into every aspect of life in highly developed countries. The cellphone I use to make plans with friends contains petroleum based plastics; the wine we drink with dinner and the avocados in our guacamole are imported from South America; the district heating we turn on to drive off the evening chill is generated by burning 
waste. None of these activities emit GHGs directly, but they would be impossible without them. None of these activities are unusual or noteworthy, and I am not consciously aware of the emissions that enable them; rather, they are components of the society in which I live that "structure[] my attention and give[] shape to my experience, like the sidewalk paths on my walk home or the favorite coffee shop that organizes my attention as I write" (Zoller, 2015, p. 1000). To refrain entirely from emissions-producing activities is nigh impossible and would demand an entirely different lifestyle; as Baatz says, "[w]ithin current carbon-dependent structure in industrialized countries, leading such a lifestyle may be connected with very high economic, social, and psychological costs; it would have rather fundamental impacts on the lives of these individuals" (2014, p. 9). This clearly asks to much: "we can have moral duties to act in certain ways only if we do not have to sacrifice something of comparable moral importance in order to comply with that duty" (Schwenkenbecher, 2014, p. 180), and continued participation in society is of great moral importance.

Perhaps a better option would be to refrain from luxury emissions. In contrast to subsistence emissions, or those emissions which are necessary to lead a decent life, luxury emissions provide amusement, comfort, convenience, or another luxury (Shue, 1993, p. 56). This formulation of individual duties would certainly reduce the amount of unnecessary GHG production by, among other things, preventing SinnottArmstrong's joyride. However, it can be difficult to determine whether an act is a luxury or subsistence emission. The concept of subsistence emissions is typically invoked to characterize emissions by poor people in the developing world, but Baatz cautions that this need not be the case (2014, p. 9). Picture Margaret, an elderly retiree in a rural area with poor public transportation. The nearest shop and all her friends are two towns over, and her physical condition is no longer adequate to make the trip by bike. Her pension is too small to consider moving. She would be unable to meet her physical and social needs without driving, so it clearly qualifies as a subsistence emission. The issue is less clearcut for Denise, her next door neighbor. Denise is a successful lawyer who recently moved to the countryside to live in fresh air and quiet. She needs to commute into the city every day for work, too far to bike, and would be unable to support her family or pay off the house without this job. Nevertheless, she moved to the country voluntarily and possesses the financial means to relocate again, so it's unclear whether her commute qualifies as a subsistence emission.

Moreover, focusing solely on luxury emissions ignores other avoidable ones. If I forget to pick up energy-efficient lightbulbs every time I visit the store, that's certainly a failure on my part that would meet Banks' epistemic condition, but isn't the same as a luxury I choose to partake in. To put it another way: electrically lighting my house can be considered a subsistence emission, at least in the context of a developed country. But there is more than one way to get that light, and I would argue that I should use the more energy efficient one. My obligation could thus be formulated as a duty to minimize avoidable emissions; that is, those which are the product of individual decisions and who can be reasonably avoided given one's societal, financial, or other circumstances. 'Reasonable' should not be taken to mean that the actions require no personal investment or 
sacrifice, however. Some actions to fulfill this duty, such as replacing a few lightbulbs, cost almost nothing and take almost no time. Upgrading to better-insulated windows demands a substantial monetary investment, biking to work instead of driving requires me to accept some inconvenience, and not going for a Sunday joyride means giving up that particular pleasure, but all are emphatically reasonable actions for me to take. The societal infrastructure exists that would allow me to take such actions without removing myself from it.

The specific actions demanded by this formulation of the duty are vague by design, to account for case-by-case differences in individual circumstances. Margaret and Denise have different means at their disposal despite their proximity, so what emissions-reducing actions are reasonable must be determined by each of them individually. This is consistent with Baatz's discussion of how to determine what amount of personal emissions reduction is fair, where he states that it is impossible to come to a general conclusion about how much an individual can be required to reduce their emissions $(2014$, p. 11). However, he cautions that emissions reduction should not be left to the judgment of individuals as a sort of optin public service. Reducing emissions is not merely the "morally better" course of action, as Sinnott-Armstrong implied it might be (2005, p. 296), but is in fact the morally required one. It is left to individuals to determine what reductions are reasonable for themselves, but not whether such reductions are necessary. The duty demanded by this obligation is an imperfect one, a fact that deserves further elaboration. By Baatz's reading, the distinction between perfect and imperfect duties hinges on "whether or not ethics can specify when the duty is fulfilled" (2014, p. 13). He provides giving donations to the poor as an example of a positive imperfect duty. I have a moral duty to aid the poor, but my duty is not finished after one donation; the limits of the aid I can give have not been reached and likely never will be, and there are no ethical guidelines by which to judge when I've given enough. Reducing my emissions is, then, a negative imperfect duty. I have a duty to not emit GHGs, but refraining from emitting for one day does not mean I have reduced my emissions enough.

If the criteria for fulfilling an imperfect duty are unclear, a natural corollary is that the boundaries for failing to comply with it are similarly diffuse. To illustrate this point, let us examine a perfect negative duty: not to commit murder. As long as I have not killed anyone, I am fulfilling this duty, but the instant that I, with malice aforethought, end somebody else's life, I am no longer complying with it. Not so with climate change. If I ride my bike most days but, running late on an icy, ugly day, decide to take my car, I have not suddenly failed to reduce my emissions. No single act or failure to act determines whether I am fulfilling my obligation, but rather the pattern of my actions. As long as I tend to ride my bike, I'm fine. The patterns of actions and choices that make up day-to-day life are, in a word, my habits, so I will reformulate my duty one final time: I am obliged to cultivate green habits. So to answer Sinnott-Armstrong's question of whether climate change provides moral grounds to refrain from his Sunday joyride: there is no obligation to refrain from a joyride on this particular Sunday, but there is an obligation not to make a habit of it. 


\section{Conclusion}

To summarize my arguments thus far: Objections to an individual obligation to reduce emissions that focus on a single emitting act fundamentally misrepresent the nature of individual contributions to climate change. Even if an act is not harmful in isolation, it can become harmful in aggregate, and in such a case any instance of that act is non-superfluously helping to bring the aggregate harm about. Groups of individuals performing such an act en masse are responsible for the harms that arise as a result, regardless of whether the group is coordinated or whether its members are aware of their membership. Individual members of these putative groups assume a moral obligation to address the harm for which they are collectively responsible. Because emissions can accumulate indefinitely, obligations to reduce them constitute an imperfect moral duty, making that reduction an ongoing process and compelling individuals to develop green habits.

Even if my arguments fail to persuade and Sinnott-Armstrong's first premise stands, there are compelling grounds to reject his second premise that there can be no obligation to act or refrain from acting if doing so won't make a difference. Baatz, for instance, makes the fairness-based argument that each individual is only entitled to emit a proportional amount of the global carbon budget; people who emit more than their fair share are then morally obligated to reduce their emissions until they reach that threshold (2014, p. 5). Hourdequin takes a virtue ethics approach, arguing that to maintain moral integrity, it is important that individual behavior align with political beliefs and public statements-in working towards systematic reductions of emissions, individuals must also reduce their own (2010, p. 450). Knights also relies on virtue ethics to refute the premise, arguing that remaining a member of a group causing harm, by choice, is in fact immoral (2019, p. 529). In each of these accounts, it is immaterial whether an individual act makes a difference or not; they may well be insignificant, but individuals have a duty to reduce their personal emissions regardless.

Compared to the scale of climate change, the effect of individual emissions reductions will be minor; it is certainly not the solution to climate change. But minor as its direct effects may be, they cannot be overlooked. Any emissions not emitted are helping ameliorate the harms of climate change. Moreover, any emissions-reducing activity may have positive indirect effects which I have not examined here. By serving as a moral role model (Hourdequin, 2010, p. 454) or raising awareness (Schwenkenbecher, 2014, p. 179), one may inspire others to reduce their own emissions, starting a positive feedback loop of green behavior.

Reducing personal emissions through green habits should also not be treated as the only individual duty we have regarding climate change. By focusing solely on individual emissions, I have ignored the importance of broader collective action or systemic change. These are vital to successfully mitigate the effects of climate change, and individuals may be obliged to work towards bringing them about by voting green (Maltais, 2013, p. 9), putting politicians to task (Sinnott-Armstrong, 2005, p. 312), or joining environmental organizations (Fahlquist, 2009, p. 121). Minimizing our own emissions is only the beginning. 
Funding Open access funding provided by University of Graz..

Open Access This article is licensed under a Creative Commons Attribution 4.0 International License, which permits use, sharing, adaptation, distribution and reproduction in any medium or format, as long as you give appropriate credit to the original author(s) and the source, provide a link to the Creative Commons licence, and indicate if changes were made. The images or other third party material in this article are included in the article's Creative Commons licence, unless indicated otherwise in a credit line to the material. If material is not included in the article's Creative Commons licence and your intended use is not permitted by statutory regulation or exceeds the permitted use, you will need to obtain permission directly from the copyright holder. To view a copy of this licence, visit http://creativecommons.org/licen ses/by/4.0/.

\section{References}

Baatz, C. (2014). Climate change and individual duties to reduce GHG emissions. Ethics, Policy, and Environment, 17(1), 1-19.

Banks, M. (2013). Individual responsibility for climate change. The Southern Journal of Philosophy, $51(1), 42-66$.

Benhelal, E., et al. (2013). Global strategies and potentials to curb $\mathrm{CO}_{2}$ emissions in the cement industry. Journal of Cleaner Production, 51, 142-161.

Cripps, E. (2011). Climate change, collective harm and legitimate coercion. Critical Review of International Social and Political Philosophy, 14(2), 171-193.

Fahlquist, J. N. (2009). Moral responsibility for environmental problems-Individual or institutional? Journal of Agricultural and Environmental Ethics, 22, 109-124.

Hiller, A. (2011). Climate change and individual responsibility. The Monist, 94(3), 349-368.

Hourdequin, M. (2010). Climate, collective action, and individual ethical obligations. Environmenal Values, 19(4), 443-464.

IPCC. (2018) 'Global Warming of $1.5^{\circ} \mathrm{C}$. An IPCC Special Report on the impacts of global warming of $1.5^{\circ} \mathrm{C}$ above pre-industrial levels and related global greenhouse gas emission pathways, in the context of strengthening the global response to the threat of climate change, sustainable development, and efforts to eradicate poverty', Available at: https://www.ipcc.ch/sr15/download/ (Accessed: 14 November 2019).

Knights, P. (2019). Inconsequential contributions to global environmental problems: A virtue ethics account. Journal of Agricultural and Environmental Ethics, 32, 527-545.

Lee, T. M., Markowitz, E. M., \& Leiserowitz, A. A. (2015). Predictors of public climate change awareness and risk perception around the world. Nature Climate Change, 5, 1014-1020.

Maltais, A. (2013). Radically non-ideal climate politics and the obligation to at least vote green. Environmental Values, 22(5), 589-608.

Mechler, R. et al. (eds) (2019) Loss and Damage from Climate Change. Climate Risk, Policy, and Governance. https://doi.org/10.1007/978-3-319-72026-5 (Accessed: 14 November 2019).

Nefsky, J. (2017). How you can help, without making a difference. Philosophical Studies, 174, $2743-2767$.

Nefsky, J. (2019) 'Collective harm and the inefficacy problem', Philosophy Compass, 14. https://doi.org/ 10.1111/phc3.12587 (Accessed: 16 November 2019).

Schwenkenbecher, A. (2014). Is there an obligation to reduce one's individual carbon footprint? Critical Review of International Social and Political Philosophy, 17(2), 168-188.

Shue, H. (1993). Subsistence emissions and luxury emissions. Law \& Policy, 15(1), 39-59.

Sinnott-Armstrong, W. (2005). It's not my fault: Global warming and individual moral obligations. Perspectives on Climate Change, 5, 293-315.

Zoller, D. (2015). Moral responsibility for distant collective harms. Ethical Theory and Moral Practice, $18,995-1010$.

Publisher's Note Springer Nature remains neutral with regard to jurisdictional claims in published maps and institutional affiliations. 